\title{
Unusual intramuscular locations as a first presentation of hydatid cyst disease in children: a report of two cases
}

Ruba A. Khasawneh ${ }^{1 *}$ (D) Ziyad M. Mohaidat ${ }^{2}$, Rawand A. Khasawneh ${ }^{3}$, Sohaib B. Zoghoul ${ }^{4}$ and Yousef M. Henawi ${ }^{1}$

\begin{abstract}
Background: Hydatid disease is an endemic disease in many countries of the world including the Middle East. It mainly affects the liver and lungs. Intramuscular hydatid disease is rarely reported in children. Such uncommon localization of hydatid cyst may pose difficulties in the clinical and radiological diagnosis; hence affecting patient's management and outcome even in endemic areas.
\end{abstract}

Case presentation: We herein describe intramuscular hydatid cysts in 2 different children. The first case is a 5-yearold boy who presented with a painless palpable lump over the right lumbar paraspinal region. His history was remarkable for sheep contact. His laboratory results revealed a mild increase in white blood cell (WBC) count and Creactive protein. The lesion showed typical features of a hydatid cyst on ultrasound. Further imaging including ultrasound of the abdomen and CT of the chest, abdomen, and pelvis showed infestation of the liver and lung as well. The lesions were resected surgically without complications. The patient received Albendazole preoperatively and after surgery for 3 months. No evidence of recurrence was seen during follow-up.

The second case is a 6-year-old girl who presented with an incidental palpable lump in her left thigh during her hospital admission for recurrent meningitis. Ultrasound and MRI imaging were performed demonstrating a unilocular cystic lesion in the left proximal rectus femoris muscle. A provisional diagnosis of hematoma vs. myxoma was given. Biopsy was performed and yielded blood products only. The lesion was resected surgically with a postoperative diagnosis of hydatid cyst. Blood tests performed afterward showed a positive titer for Echinococcus. The patient received Albendazole for 3 months. No evidence of recurrence was seen during follow-up.

Conclusions: Despite its rarity; skeletal muscle hydatid cyst should always be considered in the differential diagnosis of cystic muscle lesions in children in endemic areas even if imaging studies did not show any of the typical signs. This will improve patient outcome by preventing unnecessary cystic puncture which might lead to serious complications, such as anaphylaxis and local dissemination.

Keywords: Hydatid cyst, Pediatric, Intramuscular, Paraspinal muscle, Thigh hydatid cyst, Case report

\footnotetext{
* Correspondence: rakhasawneh2@just.edu.jo

'Department of Diagnostic Radiology and Nuclear Medicine, Faculty of

Medicine, King Abdullah University Hospital, Jordan University of Science and Technology, Irbid 22110, Jordan

Full list of author information is available at the end of the article
}

(C) The Author(s). 2021 Open Access This article is licensed under a Creative Commons Attribution 4.0 International License, which permits use, sharing, adaptation, distribution and reproduction in any medium or format, as long as you give appropriate credit to the original author(s) and the source, provide a link to the Creative Commons licence, and indicate if changes were made. The images or other third party material in this article are included in the article's Creative Commons licence, unless indicated otherwise in a credit line to the material. If material is not included in the article's Creative Commons licence and your intended use is not permitted by statutory regulation or exceeds the permitted use, you will need to obtain permission directly from the copyright holder. To view a copy of this licence, visit http://creativecommons.org/licenses/by/4.0/ The Creative Commons Public Domain Dedication waiver (http://creativecommons.org/publicdomain/zero/1.0/) applies to the data made available in this article, unless otherwise stated in a credit line to the data. 


\section{Background}

Echinococcus Granulosus is a well-known tapeworm causing hydatid disease which is an endemic and a common public health problem in many countries of the Middle East, Mediterranean region, Africa, Asia, South America, and Australia [1-8]. Liver and lung hydatid disease constitute the majority in affected patients $[1,3-$ 7, 9-17]. Still, hydatid disease can occur rarely in other viscera and much rarer in skeletal muscles $[2,3,6]$. Intramuscular infestation can pose difficulties in the diagnosis and the management as it lacks the typical clinical appearance especially if isolated [7]. Furthermore, intramuscular hydatid cyst can mimic abscess, hematoma, lymphatic malformation, synovial cyst as well as necrotic malignant soft tissue mass lesions [18-20]. Scarce studies have reported intramuscular hydatid cyst in children [7, 8, 15, 18, 21-24]. Herein we report rare localizations of hydatid cyst disease in the paraspinal and proximal thigh muscles in two different children; one of whom presented with an isolated primary intramuscular hydatid cyst.

The case reports in this study are presented in line with the CARE criteria [25].

\section{Case (1) presentation}

A 5-year-old male presented to the pediatric surgery clinic with a slowly growing painless lump in the right side of the lumbar region over 6-months. The lump was bothering him while walking and sitting. No history of trauma at the site of the lump was recalled. The systemic review was negative for any other complaints. On clinical examination, the mass was firm with no elicitable tenderness. No overlying skin changes were noticed.

His blood tests were all normal except for a mild increase in white blood cell count (WBC) $(12 \times 10 * 3 /$ $\mathrm{mm}^{*} 3$ ) and C-reactive protein $(48 \mathrm{mg} / \mathrm{L})$. Ultrasound exam showed a well-defined thick encapsulated cystic mass lesion in the right paraspinal muscle measuring about $2.4 \times 1.7 \mathrm{~cm}$. Water Lilly sign membrane was seen within it (Fig. 1a). Multiple small cysts (daughter cysts) and hyperemia of its capsule on Doppler images were also demonstrated (Fig. 1b). A provisional diagnosis of intramuscular hydatid cyst was made. Further history revealed that the patient had close contact with sheep. Abdominal ultrasound showed multiple hydatid cysts in the liver. Computed Tomography (CT) scan of the chest, abdomen, and pelvis re-demonstrated the liver (Fig. 2a) and right paraspinal muscle hydatid cysts. In addition, a well-defined multi-loculated cystic lesion was seen at the medial segment of the right middle lung lobe with an adjacent area of collapse consolidation, representing a complicated hydatid cyst (Fig. 2b). Enhanced lumbar spine Magnetic Resonance Imaging (MRI), was ordered for preoperative planning. It showed the right paraspinal hydatid cyst as a cystic lesion spanning the levels of L2 to L3 vertebrae with a peripheral thick enhancing capsule, containing Water Lilly sign and daughter cysts. There was a reactive enhancement of the involved muscles as well (Fig. 3a, b). No deeper extension of the cyst was seen.

Upon radiological diagnosis, the patient was started on Albendazole $170 \mathrm{mg}$ for 1 week before surgery. Blood serology showed a negative antibody titer for the Echinococcus Granulosus (8.1) En-bloc surgical excision of the paraspinal cyst was performed. The liver and lung hydatid cysts were subsequently excised in two separate procedures through open laparotomy and thoracotomy. $\mathrm{R}$ vacuum drain was placed postoperatively for 3 days after each procedure. The patient received Albendazole (170 $\mathrm{mg}$ ) for 3 months postoperatively.

Histopathology confirmed the diagnosis of hydatid cyst disease. No recurrence was observed in the 16 months follow-up period.

\section{Case (2) presentation}

A 6-year-old female presented to the pediatric emergency room with a decrease in the level of consciousness, inability to walk, and fever. The past medical
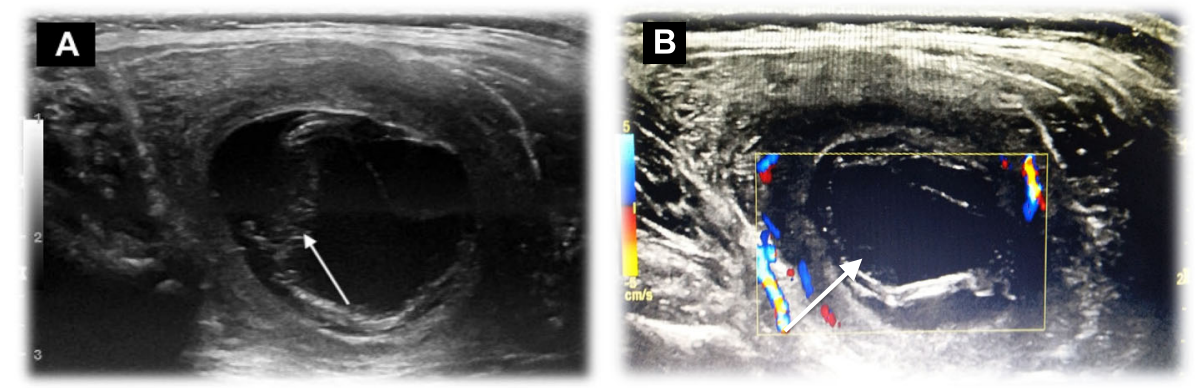

Fig. 1 Ultrasound exam of the right Paraspinal region. a: A well-defined thick encapsulated cystic lesion is seen in the right paraspinal muscle measuring about $2.4 \times 1.7 \mathrm{~cm}$ with water Lilly sign (arrow) consistent with hydatid cyst, $\mathbf{b}$ Doppler ultrasound of the same lesion showing hyperemia of the capsule and the daughter cysts (arrow) 

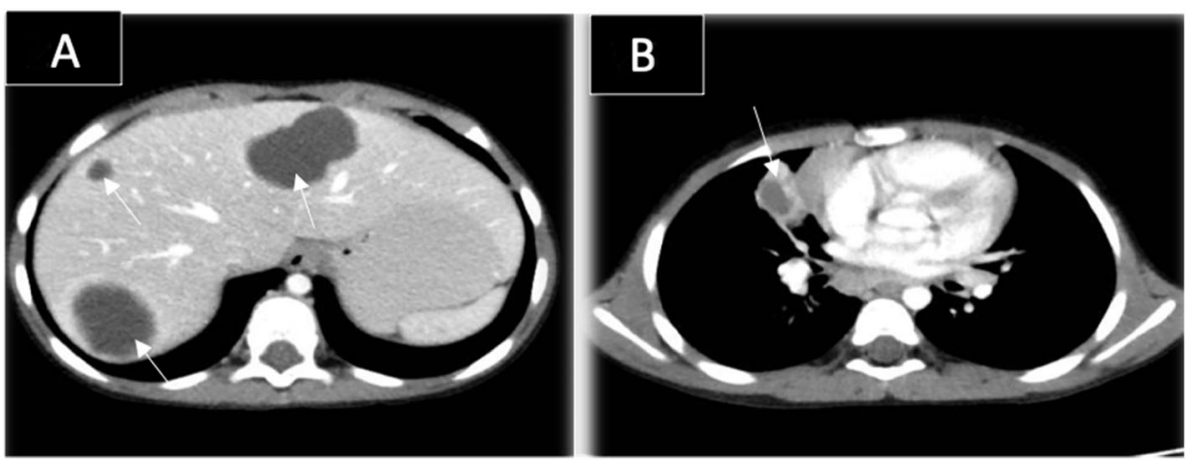

Fig. 2 Enhanced axial CT scan of the chest and abdomen. a: showing multiple liver cysts (arrows). b: showing a Multi-loculated cystic lesion in the medial segment of the right middle lung lobe with a surrounding area of collapse consolidation (arrow); representing complicated hydatid cyst

history was remarkable for documented recurrent meningitis secondary to dental problems. Physical examination showed positive meningeal signs. Her lab results including lumbar puncture showed a new attack of acute meningitis. Enhanced brain MRI was performed and was unremarkable. During her physical exam, a non-tender incidental lump was noted in the anterior aspect of her left proximal thigh. The mass was soft measuring about $5 \mathrm{~cm}$. The patient did not recall any trauma to the affected region. No discoloration of the overlying skin or palpable lymphadenopathy was noted.

Ultrasound showed a well-defined cystic lesion in the left rectus femoris muscle, with acoustic enhancement measuring about $2.7 \times 5.2 \times 2.4 \mathrm{~cm}$. The cyst abutted the superficial femoral vessels. No internal vascularity, surrounding hyperemia, or soft tissue component was seen (Fig. 4a, b). The rest of the rectus femoris muscle fibers appeared edematous. A provisional diagnosis of chronic hematoma was given. Follow-up ultrasound after a month showed the same findings with no evidence of involution. Hence, an enhanced MRI of the left thigh was recommended to exclude other serious conditions. MRI revealed a well-defined oval-shaped intramuscular homogenous cystic lesion with no perceptible wall enhancement. (Fig. 5a, b). The given differential diagnosis for this incidental isolated intramuscular cyst was chronic hematoma versus intramuscular myxoma, despite its rarity in the pediatric age group.

A biopsy was advised. Aspirate of the cyst was performed and yielded blood cells only. The orthopedic surgeon decided to proceed with wide local excision. The mass was excised through an anterior proximal thigh incision overlying the mass. After isolating the femoral vessels, the mass was dissected out of the surrounding tissues and excised without rupture.

Surprisingly, histopathology came back as an intramuscular hydatid cyst. No history of animal contact was found upon further questioning. In a retrospective review of the MRI images, a faint water Lilly sign membrane on STIR images was recognized (Fig. 5a). Further laboratory exams showed a positive antibody titer for the Echinococcus Granulosus (30.1). CT scan of the chest, abdomen, and pelvis did not reveal any other organ infestation. The patient was started on oral Albendazole (170) mg for 3 months. No recurrence was noted during the 2 years follow-up period.

\section{Discussion and conclusions}

Hydatid disease of the musculoskeletal system is rare with a reported incidence of about $1-5 \%[3,5,11,12]$.
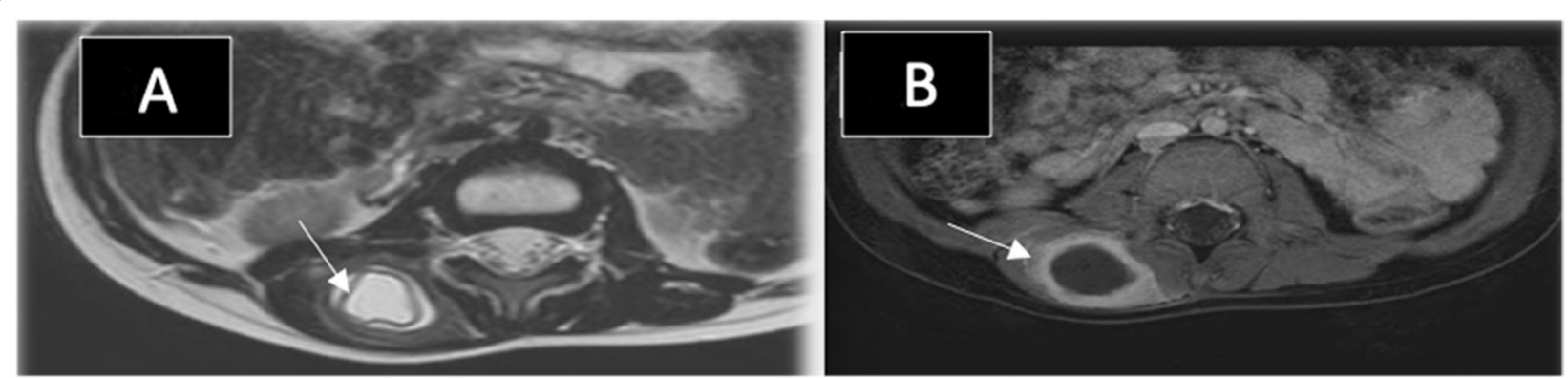

Fig. $3 \mathrm{MRI}$ of the lumbar spine in the axial planes. a: Axial T2 weighted images demonstrating the right Paraspinal hydatid cyst with water Lilly sign (arrow). b: Axial T1 postcontrast MRI with fat sat showing thick enhancement of the cyst capsule (arrow) 


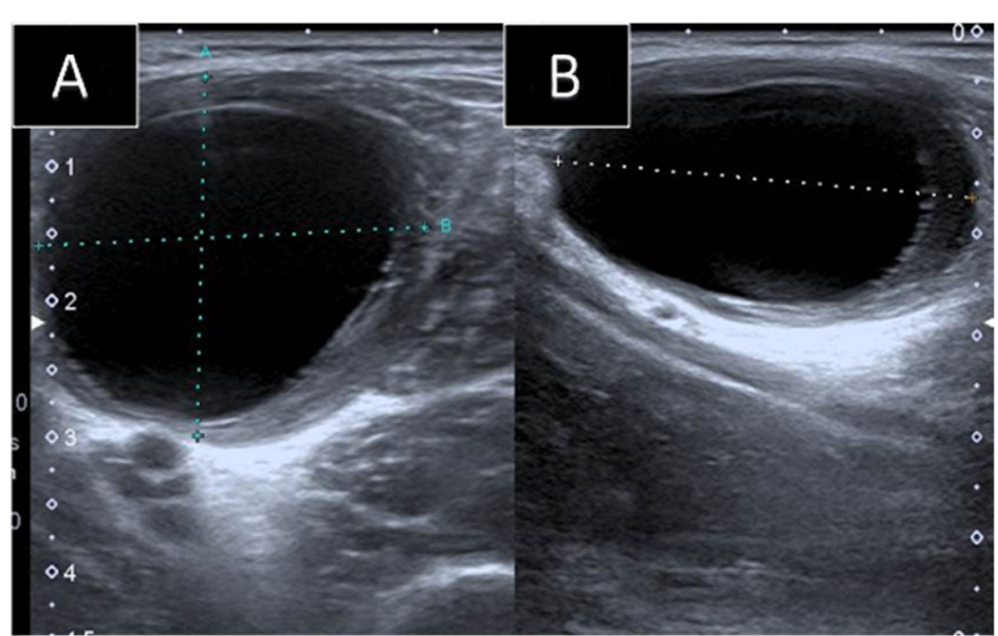

Fig. 4 Ultrasound images of the left thigh. a: Trans, b: longitudinal: Showing a well-defined homogenous cystic lesion in the left rectus femoris muscle with posterior acoustic enhancement seen

Primary intramuscular hydatid disease without liver and lung involvement is even rarer with an incidence of about $2-3 \%[4,10,14]$. Few cases of lower limb isolated intramuscular hydatid cysts were reported in the literature in the pediatric age group (Table 1). None of the reported cases, however, were in the left rectus femoris muscle as seen in this study (case (2) presentation) (Table 1). Paraspinal muscles are much more rarely affected in hydatid disease [14]. Herein, we also report an unusual localization of hydatid cyst in the right paraspinal muscle, which was not reported before in pediatric patients (Fig. 1a, b and Fig. 3a, b). (Table 1). The reason behind the rare occurrence of hydatid cyst in skeletal muscles is their frequent contractility and high lactic acid content $[1,3-5,7,9,10,13-16,19]$.

The average age for most of the cases reported in the literature was adult to middle age groups [1]. Scarce cases of intramuscular hydatid cyst were reported in children (Table 1). Both of the cases presented here were seen in the pediatric age group, adding to the challenge in diagnosis and treatment.

Intramuscular hydatid disease is frequently asymptomatic [15]. Painless slow-growing mass with normal overlying skin is the most commonly reported complaint in the literature $[7,10,12,13]$. This is similar to the clinical presentation of the patients presented in this report.

Imaging plays a major role in diagnosing intramuscular hydatid cysts when typical imaging features are present. Ultrasonography is a major non-invasive tool to confirm the diagnosis of hydatid disease [7]. Typical ultrasound imaging features include the pathognomonic daughter cysts [16]. Double line sign is another characteristic sign in Ultrasound of hydatid cysts [7].

The CT appearance of the hydatid cyst is variable [5]. Hydatid cyst on CT may mimic tumor if presented as a solid mass secondary to inflammatory changes [5].
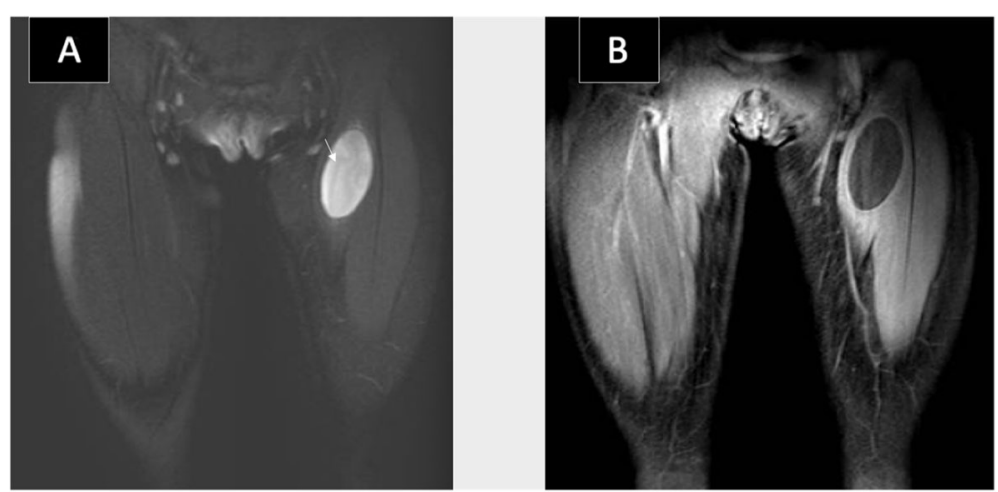

Fig. $5 \mathrm{MRI}$ of the thighs in coronal planes. a: STIR MRI image showing a well-defined cystic lesion with faint water Lilly sign (arrow) seen in the left rectus femoris muscle. $\mathbf{b}$ : T1 postcontrast image with fat saturation showing no perceptible enhancement of the lesion 
Table 1 Literature review of pediatric intramuscular hydatid cysts

\begin{tabular}{|c|c|c|c|c|c|c|}
\hline Author & Age• & Sex & Location & $\begin{array}{l}\text { Presenting } \\
\text { symptom }\end{array}$ & $\begin{array}{l}\text { Isolated vs. } \\
\text { Multiple }\end{array}$ & $\begin{array}{l}\text { Uniloculated vs. } \\
\text { Multiloculated. }\end{array}$ \\
\hline \multirow[t]{2}{*}{ Tekin et al [7] } & 10 & Female & Thigh M & Painless mass & Isolated & NA \\
\hline & 6 & Female & Thigh M & Painless mass & Isolated & NA \\
\hline Ghoroobi et al [15] & 5 & Male & Left Posterior distal thigh & Painless swelling & Isolated & Uniloculated \\
\hline Atalar et al [8] & 4 & Female & Left Vastus Medialis M & Painless mass & Isolated & Uniloculated \\
\hline Erol et al [21] & 11 & Male & Right Medical Gastroc. M & Painless mass & Isolated & Uniloculated \\
\hline $\begin{array}{l}\text { Dudkiewez et al } \\
\text { [22] }\end{array}$ & 14 & Male & Right Vastus Medialis M & Painless mass & Multiple & NA \\
\hline Duygulu et al [20] & 8 & Female & Left Sartorius M & Painless mass & Isolated & Multiloculated \\
\hline Landolsi et al [24] & 8 & Male & Left semitendinosus $M$ & Painless mass & Isolated & Multiloculated \\
\hline $\begin{array}{l}\text { Kerimoglu et al } \\
{[18]}\end{array}$ & 8 & Female & Left flexor halluces longus M & Painful swelling & Isolated & Multiloculated \\
\hline $\begin{array}{l}\text { Cankorkmaz et al } \\
\text { [23] }\end{array}$ & 4 & Female & $\begin{array}{l}\text { Between left adductor } M \text { and } \\
\text { iliopsoas M }\end{array}$ & Painless mass & Isolated & Uniloculated \\
\hline
\end{tabular}

M Muscle, Gastroc. Gastrocnemius, NA not available

$\because$ Years

However, the presence of daughter cysts, germinal epithelium detachment, and wall calcifications may confirm the diagnosis [7]. CT is also superior for the assessment of bone invasion by the cysts [7].

MRI has a major diagnostic role in assessing the extent of skeletal muscle infestation, exclude other possible etiologies, and for surgical planning $[1,10,14,16]$. MRI can reveal a cystic mass containing daughter cysts, rim sign, and Water Lilly sign $[6,17]$. The rim sign is considered a characteristic sign in muscular hydatidosis $[5,8]$. It is defined as a low signal intensity rim seen around the cyst, likely formed by the peri-cyst, most evident on T2 weighted images (WI's).

The diagnosis of hydatid cyst was made easily by imaging in the first case despite its atypical clinical presentation. Daughter cysts and Water Lilly sign were seen in all imaging modalities. The diagnosis was also supported by the patient's positive history of sheep contact and coincident liver and lung cysts upon further imaging.

The diagnosis in the second case, however, was more challenging. The possibility of an intramuscular hydatid cyst was not raised neither clinically nor radiologically. Biopsy was also performed and was not diagnostic. The final diagnosis came out only after surgical resection and histopathological analysis. Its ultrasound imaging appearance as a unilocular mostly homogenous cystic lesion (Fig. 4a, b) may reflect on the initial stage of parasitic infestation in muscles [5].

Serological tests, like the indirect hemagglutination assay test (IHA), can be valuable in making the diagnosis when they are positive [16]. Unfortunately half of the primary skeletal muscle hydatidosis gives false -negative results in serology $[8,14,16,19]$. The serology in the first presented case was negative despite multi-organ infestation, while it was positive in the second case although it was an isolated intramuscular hydatid cyst.

There are multiple treatment options for hydatid cyst. En bloc surgical resection is considered the treatment of choice with lower complications and recurrence rates $[2$, $4,14]$. Other Options include PAIR (percutaneous aspiration injection-re-aspiration); which showed promising results lately; medical treatment (Albendazole), and watch and wait [2]. Both patients in this series were treated with en bloc surgical resection along with Albendazole before and after surgery in the first case, while only after surgery in the second case, as the diagnosis was revealed only after surgery.

In conclusion; pediatric intramuscular hydatid cyst is rare. A painless lump is the usual clinical presentation. Radiology plays a crucial role in making the diagnosis of hydatid cyst when typical imaging features are seen. Surgery, and chemotherapy are the standard treatment options. Atypical clinical and radiological findings may result in mismanagement of the patient leading to serious complications. Intramuscular hydatid cyst should be kept in the differential diagnosis for any cystic muscular lesion in endemic areas.

\section{Abbreviations}

WBC: White Blood Cell; CT: Computed Tomography; MRI: Magnetic Resonance Imaging; STIR: Short Tau Inversion Recovery; WI's: Weighted images; IHA: Indirect Hemagglutination Assay; PAIR: Percutaneous Aspiration Injection Re-aspiration

\section{Supplementary Information}

The online version contains supplementary material available at https://doi. org/10.1186/s12887-021-02843-5.

Additional file 1. Timeline for case 1. 
Additional file 2. Timeline for case 2 .

\section{Acknowledgments}

Not applicable.

\section{Authors' contributions}

RK: Design of the work, acquisition of Data, wrote the manuscript, corresponding author. ZM: Design of the work, wrote the manuscript, revision of the manuscript. RAK: Acquisition of Data, wrote the manuscript, revision of the manuscript. SZ: Acquisition of Data, wrote the manuscript, revision of the manuscript. $\mathrm{YH}$ : Acquisition of Data, wrote the manuscript, revision of the manuscript. All authors have read and approved the final manuscript.

\section{Funding}

No funding was obtained for this manuscript.

\section{Availability of data and materials}

All data generated or analyzed during this study are included in this manuscript and its supplementary information files.

\section{Declarations}

Ethics approval and consent to participate

Ethics approval and consent to participate are waived for case reports per our Jordan University of Science and Technology institutional regulations.

\section{Consent for publication}

Written informed consent was obtained from the patients' parents for publication of these case reports and accompanying images. Copies of the consent forms are available for review by the Editor-in-chief of this journal upon request.

\section{Competing interests}

The authors declare that they have no competing interests.

\section{Author details}

'Department of Diagnostic Radiology and Nuclear Medicine, Faculty of Medicine, King Abdullah University Hospital, Jordan University of Science and Technology, Irbid 22110, Jordan. ${ }^{2}$ Orthopedic Division, Special Surgery Department, Faculty of Medicine, Jordan University of Science and Technology, Irbid 22110, Jordan. ${ }^{3}$ Department of Clinical Pharmacy, Faculty of Pharmacy, Jordan University of Science and Technology, Irbid 22110, Jordan. ${ }^{4}$ Radiology Department, Hamad Medical Corporation (HMC), Doha, Qatar 00000 .

\section{Received: 22 September 2020 Accepted: 17 August 2021} Published online: 31 August 2021

\section{References}

1. Comert RB, Aydingoz U, Ucaner A, Arikan M. Water-lily sign on MR imaging of primary intramuscular hydatidosis of sartorius muscle. Skelet Radiol. 2003; 32(7):420-3. https://doi.org/10.1007/s00256-003-0661-X.

2. Kurz K, Schwabegger A, Schreieck S, Zelger B, Weiss G, Bellmann-Weiler R. Cystic echinococcosis in the thigh: a case report. Infection. 2019;47(2):323-9. https://doi.org/10.1007/s15010-018-1255-9.

3. Sreeramulu PN. Krishnaprasad, Girish gowda SL. Gluteal region musculoskeletal hydatid cyst: case report and review of literature. Indian J Surg. 2010;72(S1):302-5. https://doi.org/10.1007/s12262-010-0096-2.

4. Din DPMU, Anjum WA, Ahmad ML, Rehman KA, Ahmad GB, Gulshan WN. Primary para-vertebral hydatid cyst in the sub-occipital area of the neck: an unusual case of echinococcosis. Egypt J Neurosurg. 2018;33(1):16. https:// doi.org/10.1186/s41984-018-0015-6.

5. García-Díez Al, Ros Mendoza LH, Villacampa VM, Cózar M, Fuertes MI. MRI evaluation of soft tissue hydatid disease. Eur Radiol. 2000;10(3):462-6. https://doi.org/10.1007/s003300050077.

6. Alam W, Shah F, Ali MA. Hydatid cystic disease of lumbar paraspinal muscles. Biomed J Sci Tech Res. 2017;1(6). https://doi.org/10.26717/BJSTR.2 017.01.000495
7. Tekin R, Avci A, Tekin RC, Gem M, Cevik R. Hydatid cysts in muscles: clinical manifestations, diagnosis, and management of this atypical presentation. Rev Soc Bras Med Trop. 2015;48(5):594-8. https://doi.org/10.1590/0037-86820197-2015.

8. Atalar MH, Cankorkmaz L, Koyluoglu G, Salk I. Imaging characteristics of three primary muscular hydatid cyst cases with various patterns. Kafkas J Med Sci. 2012;2:74-6. https://doi.org/10.5505/kjms.2012.76486.

9. Alaskar FA, Aldameg M. Hydatid disease with water lily sign manifesting as a soft-tissue mass in the soleus muscle of an adult woman : case report. Egypt J Hosp Med. 2018;71(3):2788-91. https://doi.org/10.12816/0045845.

10. Alatassi R, Koaban S, Alshayie M, Almogbil I. Solitary hydatid cyst in the forearm: a case report. Int J Surg Case Rep. 2018;51:419-24. https://doi.org/1 0.1016/j.ijscr.2018.09.038

11. Merkle EM, Schulte M, Vogel J, Tomczak R, Rieber A, Kern P, et al. Musculoskeletal involvement in cystic echinococcosis: report of eight cases and review of the literature. AJR Am J Roentgenol. 1997;168(6):1531-4. https://doi.org/10.2214/ajr.168.6.9168719.

12. García-Alvarez F, Torcal J, Salinas JC, Navarro A, García-Alvarez I, NavarroZorraquino M, et al. Musculoskeletal hydatid disease: a report of 13 cases. Acta Orthop Scand. 2002;73(2):227-31. https://doi.org/10.1080/000164702 753671858 .

13. Geramizadeh B. Unusual locations of the hydatid cyst: a review from Iran. Iran J Med Sci. 2013;38(1):2-14

14. El Harroudi T, Souadka A, Tijami F, El Otmany A, Jalil A. Primary paraspinal hydatid cyst: a case report. Internet J Orthop Surg. 2012;13:13-6.

15. Ghoroobi J, Mohajerzadeh L, Mirshemirani A, Mahdavi A. Primary hydatid cyst of thigh: a case report in child. J Krishna Inst Med Sci Univ. 2017;6:1113.

16. Durakbasa M, Kose $\mathrm{O}$, Islam N, Kilicoglu G. A primary hydatid cyst of the gracilis: a case report. J Orthop Surg. 2007;15(1):118-20. https://doi.org/10.11 $77 / 230949900701500127$

17. Sener R, Calli C, Kitis O, Yalman O. Multiple, primary spinal-paraspinal hydatid cysts. Eur Radiol. 2001;11(11):2314-6. https://doi.org/10.1007/s0033 00000771

18. Kerimoglu U, Kapicioglu S, Emlik D, Arazi M, Ural O. Case 161: hydatid disease with water lily sign manifesting as a soft-tissue mass in the calf of a child. Radiology. 2010;256(3):1007-10. https://doi.org/10.1148/radiol.10081 066.

19. Adıyeke L, Cakır T, Duymus TM, Aydogmus S. Unexpected diagnosis in gluteal region -a primary intramuscular hydatid cyst: a case report. J Orthop Case Rep. 2018;8(2):104-6. https://doi.org/10.13107/jocr.2250-0685.1072.

20. Duygulu F, Karaoğlu S, Erdoǧan N, Yildiz O. Primary hydatid cyst of the thigh: a case report of an unusual localization. Turk J Pediatr. 2006;48(3): 256-9.

21. Erol B, Tetik C, Altun E, Soysal A, Bakir M. Hydatid cyst presenting as a softtissue calf mass in a child. Eur J Pediatr Surg. 2007;17(1):55-8. https://doi. org/10.1055/s-2007-964949.

22. Dudkiewicz I, Salai M, Apter S. Hydatid cyst presenting as a soft-tissue thigh mass in a child. Arch Orthop Trauma Surg. 1999;119(7-8):474-5. https://doi. org/10.1007/s004020050025.

23. Cankorkmaz L, Ozturk H, Koyluoglu G, Atalar MH, Arslan MS. Intermuscular hydatid cyst in a 4-year-old child: a case report. J Pediatr Surg. 2007:42(11): 1946-8. https://doi.org/10.1016/j.jpedsurg.2007.07.051.

24. Maha L, Daib A, Hella Y, Boughdir M, Ben Abdallah R, Trabelsi F, et al. A rare etiology of muscular mass in infant: a case report. J Heal Med Sci. 2019;2: 275-8.

25. Riley DS, Barber MS, Kienle GS, Aronson JK, von Schoen-Angerer T, Tugwell $P$, et al. CARE guidelines for case reports: explanation and elaboration document. J Clin Epidemiol. 2017:89:218-35. https://doi.org/10.1016/j. jclinepi.2017.04.026.

\section{Publisher's Note}

Springer Nature remains neutral with regard to jurisdictional claims in published maps and institutional affiliations. 